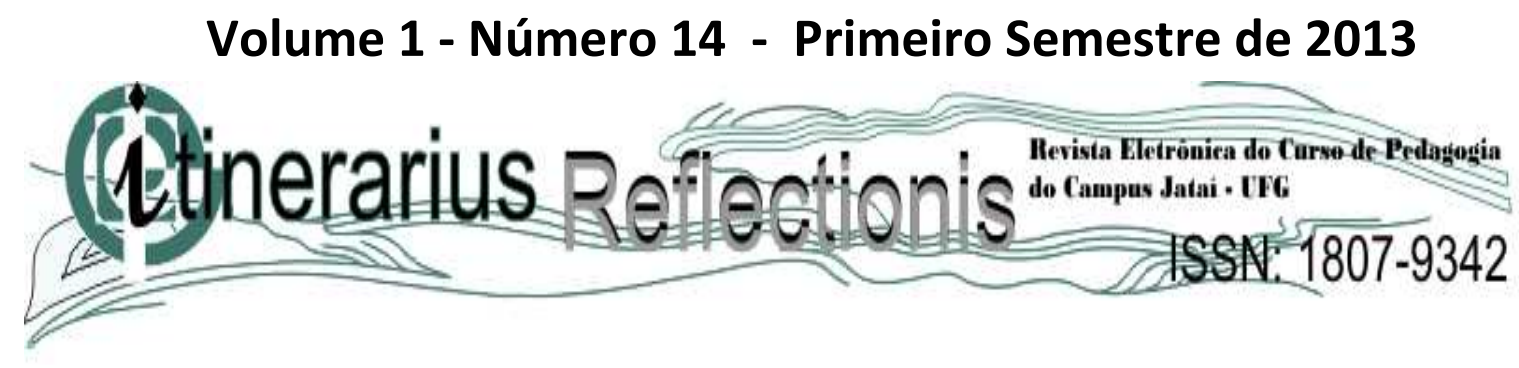

\title{
REFLEXÕES SOBRE A FORMAÇÃO DE PROFESSORES NA EDUCAÇÃO FÍSICA - LICENCIATURA
}

\author{
Cassiano Telles. Mestrando em Educação Física. \\ Universidade Federal de Santa Maria. \\ telleshz@yahoo.com.br.
}

\begin{abstract}
Aline de Souza Camarês. Mestranda em Educação Física. Universidade Federal de Santa Maria. aline_carames@hotmail.com.
\end{abstract}

Andressa Aita Ivo. Doutora em Educação. Universidade Federal de Santa Maria. dessaaita@gmail.com.

Hugo Norberto Krug. Doutor em Educação. Universidade Federal de Santa Maria. hnkrug@bol.com.br . Rua Coronel Niederauer 1537/702 - Centro - Santa Maria - RS - CEP:97.015-123.

\begin{abstract}
RESUMO: Esta investigação objetivou realizar reflexões sobre a formação de professores no âmbito da Educação Física - Licenciatura. A metodologia caracterizou-se pelo enfoque bibliográfico com abordagem qualitativa tendo como interpretação das informações uma análise documental. Ao analisarmos alguns autores: Krug, Marques, Ilha, Ivo, Marcelo Garcia, Teixeira, Nagle, Steinhilber, Lima, Nascimento, Carreiro da Costa, Saviani, Darido, Nóvoa, Luckesi, Freire e Telles, passamos a refletir sobre a prática e a linguagem, observando divergências entre os mesmos. Nossas observações mostraram perspectivas diferentes: um primeiro grupo aborda a formação como uma caça aos incompetentes; um segundo grupo como uma busca de excelência pela organização escolar como um todo e ainda outros através de objetivos, critérios, reformulação e objetivos. Verificamos que os métodos utilizados por alguns autores estão ainda fortemente presentes na escola, devido a uma corrente positivista, que ainda se encontra presente nos cursos de Educação Física - Licenciatura, como consequiência da formação adquirida pelos docentes, que ocorreu num tempo onde a cultura física era fortemente predominante. Concluímos que a formação de professores em Educação Física - Licenciatura só tem sentido se for acompanhada por uma mudança de atitudes, por uma concepção diferente da formação hegemônica atual, isto é, a formação tecnicista.
\end{abstract}

Palavras-chave: Educação Física. Licenciatura. Formação de professores. 


\title{
REFLECTIONS ABOUT THE TEACHER FORMATION IN PHYSICAL EDUCATION - DEGREE
}

\begin{abstract}
This research aimed to perform reflections about teacher formation in the context of Physical Education - Degree. The methodology was characterized by the focus bibliographic with qualitative approach having with interpretation an documentary analysis. By analyzing some authors: Krug, Marques, Island, Ivo, Marcelo Garcia, Teixeira, Nagle, Steinhilber, Lima, Birth, Carreiro da Costa, Saviani, Darido, Nóvoa Luckesi, Freire and Telles, we reflect about the practice and the language, observing divergences between them. Our observations showed different perspectives: a first group addresses the formation with as a hunting incompetent; a second group with a search for excellence by the school organization with a whole and yet others through of objectives, criteria, objectives and reformulation. Verified that the methods used by some authors are yet strongly present in the school. due the a current positivist, that yet is still present in undergraduate Physical Education - Degree, with consequence of the formation acquired by teachers, that occurred in a time where physical culture strongly predominating. We conclude that the teachers formation in Physical Education - Degree has only make sense if it is accompanied by a change in attitude, for a different conception of current hegemonic formation, this is, the technical education.
\end{abstract}

Keywords: Physical Education. Degree. Teacher formation.

\section{Considerações iniciais}

Atualmente a formação de professores vem obtendo uma posição de destaque nas discussões acadêmicas, profissionais e políticas, observando que se torna muito forte a importância de se ter uma formação inicial que venha a contribuir na preparação para 'ser docente', e consequentemente para um ensino de qualidade para os futuros professores que atuarão na escola.

É de nosso conhecimento que a formação inicial corresponde ao período que o futuro professor adquire os conhecimentos científicos e pedagógicos e as competências necessárias para enfrentar adequadamente a carreira docente (CARREIRO DA COSTA, 1994). O mesmo 


\section{Volume 1 - Número 14 - Primeiro Semestre de 2013}

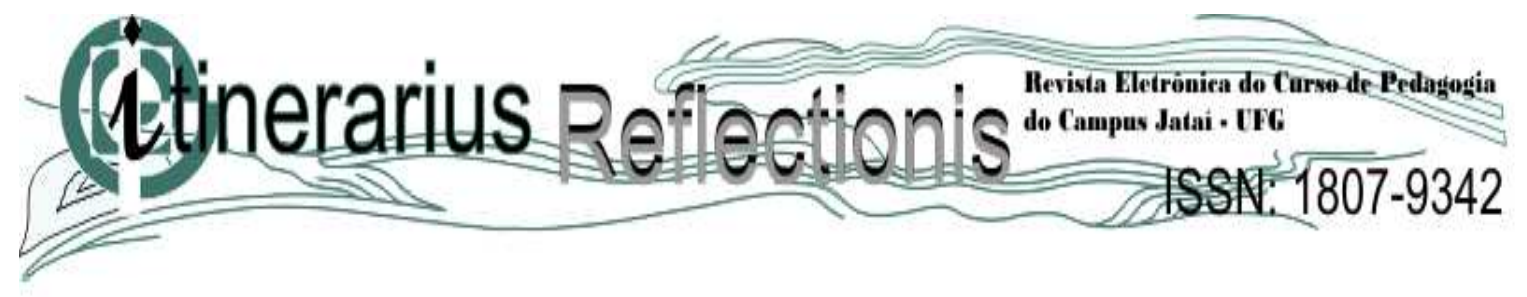

autor salienta que se essa fase de formação não promover a alteração das concepções prévias incorretas sobre a escola, a Educação Física e o ensino que os estudantes obtem e carregam com si mesmo para o curso, estas irão exercer uma influência permanente e decisiva nas suas crenças, perspectivas pedagógicas e comportamentos quando forem professores de Educação Física.

A formação dos professores em Educação Física - Licenciatura no Brasil merece destaque devido às recentes transformações que ocorreram em sua estrutura curricular a partir da promulgação da Diretrizes Curriculares Nacionais para a Formação de Professores da Educação Básica - Resolução CNE/CP n. 01 (BRASIL, 2002) e das Diretrizes Curriculares Nacionais para o Curso de Graduação em Educação Física - Resolução CNE/CES n. 07 (BRASIL, 2004), no qual definiu-se a separação das especifidades das áreas (Licenciatura e Bacharelado).

É importante ressaltar que este processo de separação vem por tentar contemplar a implementação destas novas diretrizes e restruturar os projetos pedagógicos das ações formativas, enfim, todos os aspectos que subdiziam e delineam a formação em Educação Física, tanto Licenciartura quanto Bacharelado.

A partir deste contexto, entendemos a formação de professores como um fator importante para se discutir, pois contribui para nossa própria formação, além de realizar uma possível valorização do profissional, melhorando as políticas educacionais, mesmo que essas políticas não sejam mudadas da noite para o dia.

De acordo com Krug (2010), dentro do amplo cenário de possibilidades no âmbito da formação, o Estágio Curricular Supervisionado é um importante componente curricular de grande importância para a formação profissional dos licenciandos, pois, conforme Marcelo Garcia (1999), o estágio representa uma oportunidade privilegiada para aprender a ensinar, na medida em que se integrem as diferentes dimensões que envolvem a atuação docente, ou seja, o conhecimento psicopedagógico, o conhecimento do conteúdo e o conhecimento didático do conteúdo. 


\section{Volume 1 - Número 14 - Primeiro Semestre de 2013}

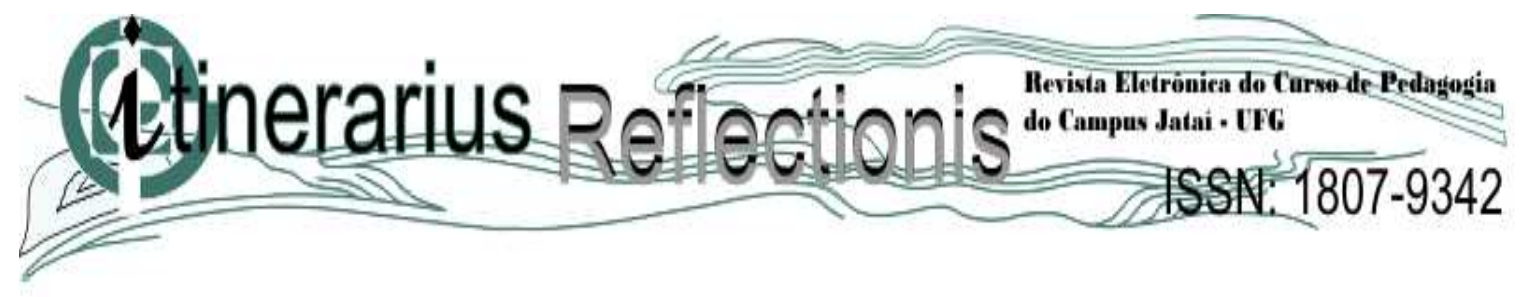

Já conforme Marques; Ilha e Krug (2009) a disciplina de Estágio Curricular Supervisionado em Educação Física. Essa tem por atribuições precípuas colocar o futuro profissional em contato com a realidade educacional, desenvolvendo-se estilos de ensino, possibilitando adequadas seleções de objetivos, conteúdos, estratégias e avaliações, entre outras finalidades. Para tanto, o Estágio Curricular Supervisionado deve fornecer subsídios para a formação do futuro professor, tanto no aspecto teórico quanto prático a fim, de que possa desenvolver um trabalho docente competente (TEIXEIRA, 1994).

Desta forma, Ivo e Krug (2008) afirmam que estudar o que e quem envolve esta disciplina é tarefa daqueles que se preocupam com uma formação de qualidade. Para Marques e Krug (2010), no meio educacional, como o contexto da formação de professores são diversas as peculiaridades que compõem os cursos de Licenciatura, estas nos permitem e nos instigam a desenvolver diversos estudos e pesquisas a fim de contribuir com a nossa própria formação, assim como fomentar questionamentos e trocas com os demais profissionais da educação e em especial da Educação Física.

Assim, considerando todas as premissas mencionadas anteriormente, traçamos como objetivo deste estudo, realizar reflexões sobre a formação de professores no âmbito da Educação Física - Licenciatura.

\section{Procedimento metodológico}

O estudo realizado se situa na perspectiva de tentar compreender a formação de professores no contexto da Educação Física - Licenciatura. E, para tanto, foi realizada uma pesquisa qualitativa que, segundo Gamboa (1995, p.61), essa proporciona a "busca de novas alternativas para o conhecimento de uma realidade tão dinâmica e polifacética como a problemática estudada".

Conforme Godoy (1995, p.21) pode-se dizer que: “[...] hoje em dia a pesquisa qualitativa ocupa um reconhecido lugar entre as várias possibilidades de se estudar os 


\section{Volume 1 - Número 14 - Primeiro Semestre de 2013}

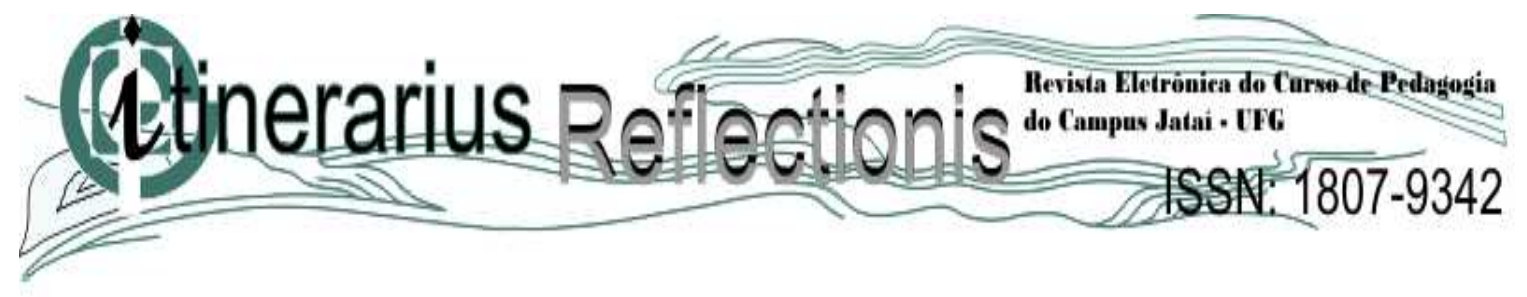

fenômenos que envolvem os seres humanos e suas intrincadas relações sociais, estabelecidas em diversos ambientes". Triviños (1987) também menciona que a pesquisa qualitativa pretende compreender uma realidade complexa, seus desejos, crenças e interesses, isto é, os acontecimentos que nela se sucedem, os quais precisam ser compreendidos como parte do todo.

Também foi realizada uma pesquisa bibliográfica que, segundo Gil (2002, p.44), “é desenvolvida com base em material já elaborado, constituído principalmente de livros, artigos científicos, periódicos e atualmente com materiais disponibilizados na internet".

Assim sendo, no primeiro momento, foi realizado um levantamento sobre a literatura que aborda o tema formação de professores - Licenciatura. No segundo momento, realizou-se leituras sobre o tema proposto. No terceiro momento, foram feitas reflexões a partir das obras encontradas e estudadas.

Portanto, o estudo foi concluído com uma análise dos escritos de alguns autores tais como: Krug, Marques, Ilha, Ivo, Marcelo Garcia, Teixeira, Nagle, Steinhilber, Lima, Nascimento, Barros, Carreiro da Costa, Saviani, Darido, Nóvoa, Luckesi, Freire e Telles.

\section{Resultados e discussões sobre algumas bases teóricas do estudo}

\section{Algumas considerações sobre a formação do docente em Educação Física - Licenciatura}

Os cursos de formação de professores de Educação Física - Licenciatura sofrem com ofensivas realizadas por estratégias mercadológicas, que vêm, através de formulações de diretrizes curriculares, reforçar a lógica pós-moderna determinando a fragmentação do conhecimento do profissional dessa área por exigência de um mercado, um mercado que a cada dia deve ser mais explorado pelo profissional. 


\section{Volume 1 - Número 14 - Primeiro Semestre de 2013}

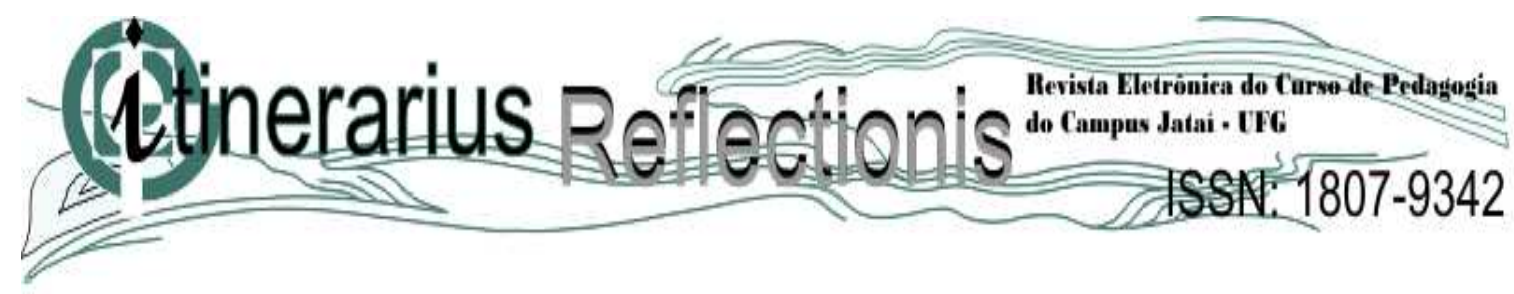

O presidente do CONFEF/CREF, em uma de suas falas diz que, precisamos ocupar as ‘terras de ninguém', antes que os outros o façam (STEINHILBER, 1996). Esse discurso de independência profissional, que sustenta nossos serviços, faz com que a descentralização do trabalho dê margem a críticas, desvalorizando nossa qualificação.

Para Nagle (1987, p.171),

[...] trabalha-se fundamentalmente com a noção de monodisciplinariedade, a qual se associa a criação de especialidades e mais especialidades, cuja conseqüência maior consiste no isolamento, de uns temas de outros, daí os proprietários do tema. Tudo isso resulta na fragmentação do conhecimento.

Estas medidas adotadas, que não podemos chamar de novas, observando que são históricas, mostram os obstáculos encontrados nos cursos de formação de professores de Educação Física - Licenciatura.

Na condição de seres humanos não podemos viver sem fazer inúmeros julgamentos que afetam nossas vidas. Assim como temos direito à satisfação de nossas necessidades, estamos sempre na busca do melhor, do aprimoramento, do conhecimento, que na nossa sociedade é o que prevalece. Esse conhecimento, que é buscado nas instituições escolares e, posteriormente, nas universidades, tem por função a disseminação do saber e, nessa função, se inclui a organização e o oferecimento de cursos de formação profissional (LIMA, 1994).

Em relação à Educação Física, a situação da formação profissional não é diferente dos demais cursos de formação de professores (DARIDO, 1995). Nesse sentido, a formação profissional em Educação Física tem se apresentado como questão de discussões, tanto na bibliografia como em encontros científicos (NASCIMENTO, 1991).

Para Barros (1995) a Licenciatura em Educação Física é voltada para a preparação profissional nos ensinos fundamental e médio, onde é enfatizado o conhecimento da motricidade humana aplicada ao fenômeno educativo, sendo esse profissional com formação de nível superior e conhecimento da área a fim, devendo possuir uma visão da função social da escola, de sua história, problemas e perspectivas na sociedade brasileira. 


\section{Volume 1 - Número 14 - Primeiro Semestre de 2013}

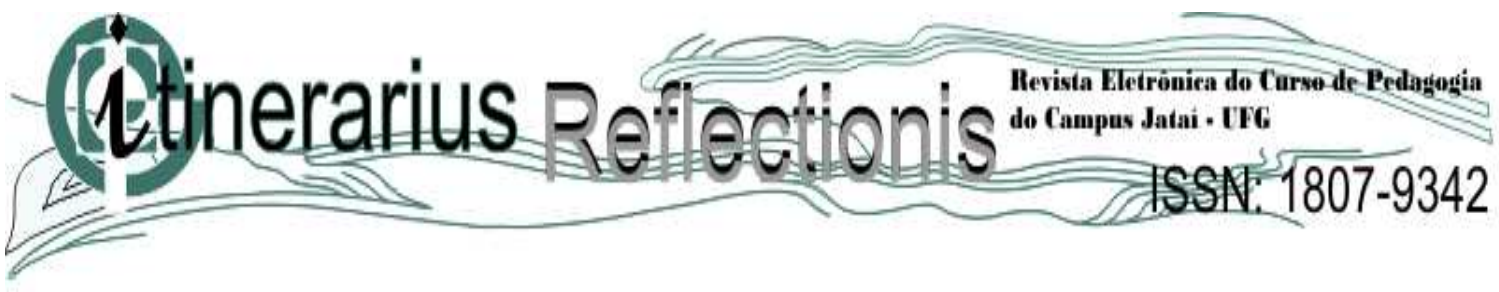

É na formação inicial que ocorre o período durante o qual o futuro professor adquiri os conhecimentos científicos e pedagógicos e as competências necessárias para enfrentar adequadamente a carreira docente (CARREIRO DA COSTA, 1994).

Para Debesse (apud PETRICA, 1987) a formação inicial é entendida como aquela que é adquirida antes da entrada em 'funções', isto é, antes do futuro professor começar a exercer a sua função docente.

$\mathrm{Na}$ perspectiva de que a formação de professores é um 'continuum', não se deve pretender que a formação inicial ofereça 'produtos acabados', encarando-a antes como uma fase de um longo e diferenciado processo de desenvolvimento profissional (MARCELO GARCIA, 1992).

Segundo evidências científicas, o ato de educar é o ato de produzir de forma intencional e direta, esta educação que está dentro de cada um, que por meio deste constrói seu próprio processo histórico de aprendizado (SAVIANI, 2005/2006).

Nesta linha de pensamento podemos deduzir que o trabalho pedagógico, a formação de professores, a reprodução do seu conhecimento, acontece a partir da superação de uma barreira cultura histórica. Essa que faz com que não sejamos um simples fantoche (aluno oprimido pelo professor que é o detentor do conhecimento), que apenas recebe a informação, nos transformando em um ser não reflexivo que não enfrenta e debate as contradições expressas na luta de classes que estão manifestadas em nosso ambiente de trabalho diário, adaptando-se a esse sistema e evitando a própria acomodação.

Para Nóvoa (1991, p.122) “a profissão docente é fortemente carregada de uma intencionalidade política", mas os cursos de formação em geral, têm privilegiado os meios de ensino, ou seja, ensinam como fazer, deixando de lado a reflexão, que virá a informar ao futuro docente para que ensinar.

Assim sendo, não se têm discutido as questões relativas às finalidades político-sociais da educação e do ensino. Podemos dizer que da forma que tem acontecido esta formação faz com que aconteça uma redução do papel de professor para se transformar em um técnico, um mero executor de conceitos elaborados por especialistas. 


\section{Volume 1 - Número 14 - Primeiro Semestre de 2013}

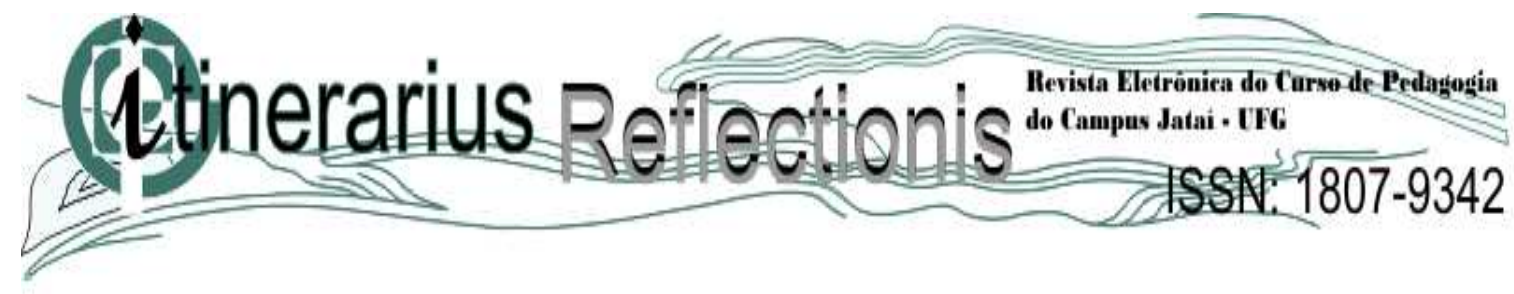

Falando um pouco sobre a cultura acadêmica da passividade, Kincheloe (1997, p.35) afirma que "os alunos e professores não são encorajados para questionar porque eles tendem a pensar como o fazem sobre eles mesmos, sobre o mundo em torno deles e suas relações com o mundo".

Com isto, professores e alunos estão, a cada dia, mais envolvidos com a cultura de manutenção do status quo, esse que não permite a diversidade, a crítica, a descoberta do novo, o inusitado.

Luckesi (1999, p.40) destaca que:

Não queremos uma universidade na qual o professor aparece como o único sujeito, o magister, o mestre que fala, diz verdades já prontas, estruturadas, indiscutivelmente certas e detém os critérios incontestáveis de certo e errado. O aluno é o ouvinte, o receptor passivo, de que é emitido pelo professormestre; sua função é, portanto, de ouvir, de aprender, isto é, memorizar e repetir bem o que lhe é transmitido. Trata-se de uma função nitidamente objetificante, porque resta ao aluno-objeto pouca ou nenhuma possibilidade de criação, de argumentação, a não ser aquela ditada pelo professor.

Com esta afirmação citamos Telles e Krug (2011) que dizem que nós, acadêmicos, estamos desejosos de novas projeções dos projetos didáticos das universidades, procurando articular o ensino, a pesquisa e a extensão, procurando qualidade no fazer. Sonhamos com uma universidade onde tudo se transforme em objetos de estudos, todos esses plausíveis de reflexão, questionamento, debates, sendo que as dúvidas entre nós acadêmicos são constantes, mas procuramos solucionar as mesmas através da construção do conhecimento, revendo concepções, princípios e ações que norteiem nossa área.

Assim, queremos destacar que acreditamos que a formação de professores de Educação Física - Licenciatura deve atentar para disponibilizar à sociedade um profissional que tenha competência para atuar na realidade social vigente e ser um agente educacional transformador dessa mesma realidade na busca de uma melhor situação de vida humana. 


\section{Volume 1 - Número 14 - Primeiro Semestre de 2013}

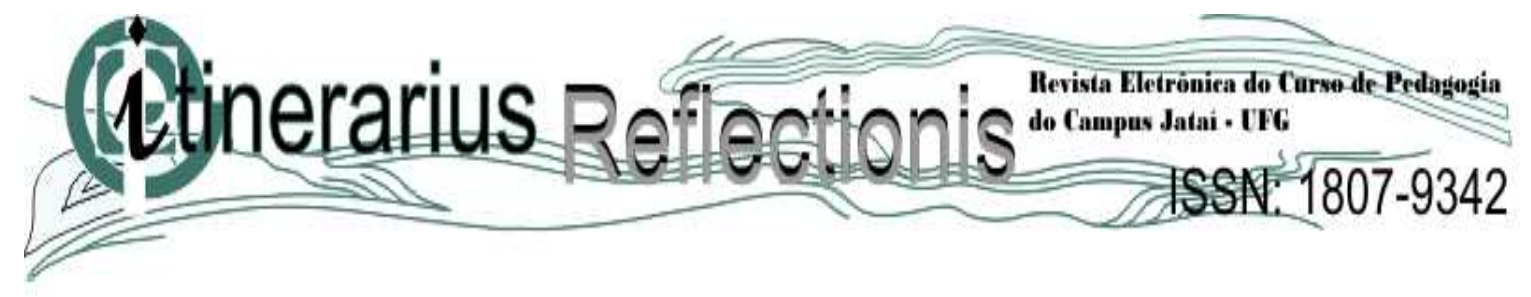

Alguns parâmetros teóricos-metodológicos para a formação do professor de Educação Física - Licenciatura

Ao observarmos a problemática que surge na análise da formação de professores de Educação Física - Licenciatura teremos que esclarecer um conjunto de fatores que constituem os parâmetros teórico-metodológicos para essa formação.

Segundo Telles e Krug (2011), para uma análise ser crítica terá que ser materializada de alguma forma, ou seja, vamos observar o real, considerando as circunstâncias históricas concretas. Por isso não podemos idealizar um modelo predeterminado como parâmetro. Precisamos obter uma visão de totalidade histórica e social, ou seja, teremos que compreender como acontece o processo de formação humana em um conjunto de produção e reprodução.

Esta seria uma situação que faria com que as pessoas acabassem com a ilusão sobre o tema, as chamando para acabar com uma situação.

Para Enguita (1993, p.86):

[...] consiste na tentativa de mudar consciências através da ação educativa [...] pois tal reformismo parte do suposto, único ou básico, de que atua sobre o educando como uma tabula rasa ou de que sua tarefa consiste em limpar seu cérebro de prejuízos pelo mesmo procedimento pelo qual os adquiriu: pela inculcação, pela ação pedagógica.

Já se pensarmos que estas premissas nos levam a um modelo reflexivo de formação de professores, teremos que conversar com Schön (1992; 2000), Zeichner (1993), Pérez Gómez (1992), que surgem através de uma crítica generalizada ao modelo de racionalidade técnica, destacando o professor como prático reflexivo, denominado como ‘ensino reflexivo' (KRUG, 2001a).

Este movimento surge em diferentes países, a partir de uma observação de uma urgente reforma educacional. Ela está ligada a três questões: o fracasso escolar, à tentativa de se entender a formação de professores diferente da racionalidade técnica, e o objetivo de fazer voltar os rumos da educação para as mãos dos professores. "A partir deste pensamento ainda 


\section{Volume 1 - Número 14 - Primeiro Semestre de 2013}

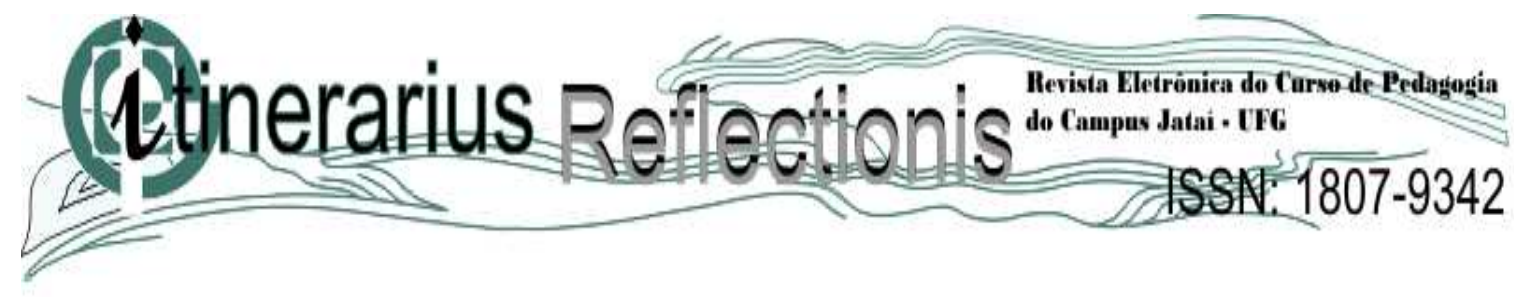

fica aberta a universidade ou aos institutos de pesquisa pensar o ensino, mas o próprio professor também tem suas teorias que podem contribuir para o conhecimento do ensino" (ZEICHNER, 1993, p.16).

Donald Schön é um dos principais autores desta corrente, defendendo a existência de um saber nas ações dos professores, que serve como referência para a formação de novos professores (ZEICHNER, 1992).

Para Pérez Gómez (1992) o processo reflexivo não é um processo individual, implica em uma imersão consciente do ser humano no mundo da sua experiência, um mundo carregado de fatores subjetivos, o conhecimento só pode ser considerado um instrumento do processo de ensino se for integrado significativamente, não se tornando algo fragmentado. $\mathrm{O}$ autor ressalta que para compreender melhor esta complexidade é necessário distinguir os processos que integram o pensamento prático:

Conhecimento na Ação: é o componente inteligente que orienta toda a atividade humana e se manifesta no "Saber Fazer". Há um tipo de conhecimento em qualquer ação inteligente, ainda que este conhecimento, fruto de reflexões passadas, se tenha consolidado em esquema semiautomáticos ou em rotina. É um conhecimento de primeira ordem. Saber fazer e explicar são duas capacidades intelectuais distintas.

Reflexão na ação: é quando pensamos sobre o que fazemos, ao mesmo tempo que atuamos. É um conhecimento de segunda ordem, isto é, um processo de diálogo com a situação problemática e sobre uma interação particular que exige uma intervenção concreta. Este conhecimento de segunda ordem encontra-se constrangido pelas pressões espaciais e temporais e pelas solicitações psicológicas e sociais do cenário em que atua. É um processo de reflexão sem rigor, a sistematização é o distanciamento requerido pela análise racional, mas com a riqueza da captação viva e imediata das múltiplas variáveis intervenientes e com grandeza da improvisação e criação, Com todas as dificuldades e limitações a reflexão é um processo de extraordinária riqueza na formação de professor prático. Quando o professor se revela flexível e aberto ao cenário complexo de interações da prática, a reflexão na ação é o melhor instrumento de aprendizagem.

Reflexão sobre a ação e sobre a reflexão na ação: é a análise que o individuo realiza "a posteriori" sobre as características e processos da sua própria ação. É a utilização do conhecimento para descrever analisar e avaliar os vestígios deixados na memória por intervenções anteriores. $\mathrm{Na}$ 


\section{Volume 1 - Número 14 - Primeiro Semestre de 2013}

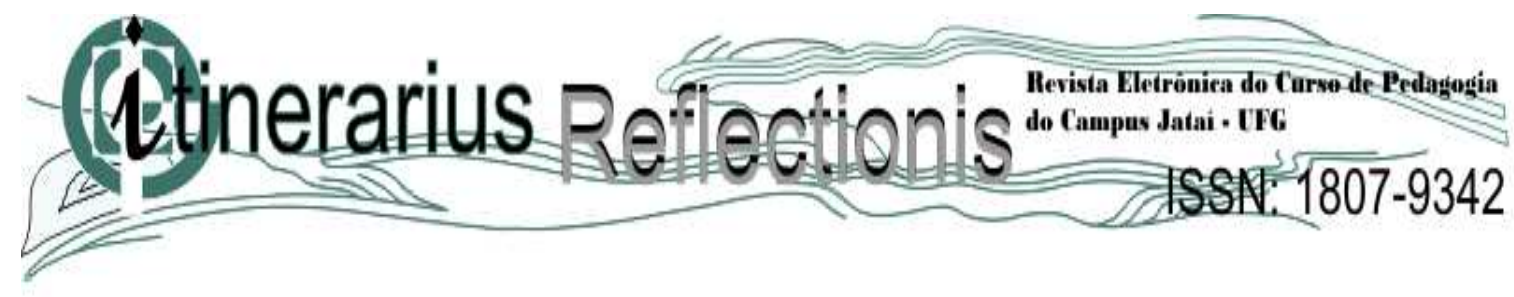

reflexão sobre a ação, o professor prático, liberto dos condicionamentos da situação prática, pode aplicar os instrumentos conceituais e as estratégias de análise no sentido da compreensão e da construção da sua prática. A reflexão sobre a ação é um componente essencial do processo de aprendizagem permanente em que consiste a formação do professor (KRUG, 2001a, p.26).

Desta forma, no processo reflexivo, o professor reflete sobre a própria ação, e assim sendo, o pensamento prático do professor é de vital importância para compreender os processos de ensino-aprendizagem, para que possamos desencadear um processo radical nos programas de formações de professores, promovendo uma qualidade no ensino da escola.

A partir disto, todos estes pensamentos nos colocam em uma situação que nos faz realmente entender todo o processo de formação existente. Trata-se de fazer com que aconteça uma busca nas tendências já existentes, muitas vezes pouco utilizadas na formação atual, fazendo-as uma possibilidade de superarmos nossas dificuldades, tentando prever como deverá ser o processo de formação futura, uma vez já liberto das travas que o impedem de refletir sobre o mesmo.

A superação exige uma transcendência do projeto histórico, fazendo com que o mesmo visualize o tema, deixando de lado toda a bagagem que fora introduzida durante a formação (opressor x oprimido) (FREIRE, 1996).

Estas análises deverão se valer de pensamentos críticos-reflexivos, cuja teoria possibilita, de modo indissociável, o conhecimento da realidade e o estabelecimento de finalidades para sua transformação. No entanto, para produzir tal transformação, não é suficiente a atividade teórica; é preciso atuar praticamente sobre a realidade, sendo que a principal forma de atuação humana é o trabalho, e assim, por meio dele, pode-se articular teoria e prática.

Frigotto (1998) referenciando a ética, fala a respeito do caráter dos interessados em pesquisa, nos mostrando que não podemos teorizar por teorizar somente e muito menos pesquisar de forma amadora e irresponsável, devemos interpretar o mundo de diferentes formas, mas não só interpretá-lo e sim transformá-lo. 


\section{Volume 1 - Número 14 - Primeiro Semestre de 2013}

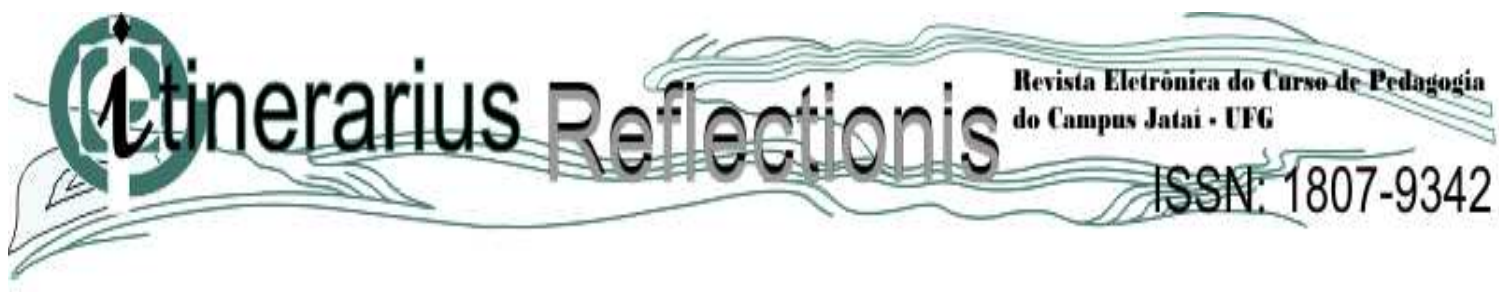

Para Krug (2001b) a comunidade acadêmica possui o desejo de transformação da prática educativa, mas ao mesmo tempo esbarra em uma prática repleta de vícios, que ainda se pautam em propostas velhas e ultrapassadas, que estão envolvidas, criando uma certa imobilidade neste profissional, não o permitindo avançar para uma prática educacional voltada para reflexão.

O estágio e a oportunidade do acadêmico desenvolver seus conhecimentos

O Estágio é a grande oportunidade do acadêmico de intervir em diferentes realidades de sua ampla atuação. Este momento irá requerer de um claro embasamento sobre a teoria e a prática, elementos norteadores que determinam o conhecimento aplicado na prática.

Este claro embasamento estará norteado por todas as disciplinas do curso, não as denominando como práticas ou teóricas e sim utilizando dos conhecimentos e métodos de todas, neste processo de aprendizagem. E é neste processo que devemos superar a distância existente entre a teoria-prática.

Assim, partimos do pressuposto destacado por Pimenta e Lima (2004) de que o Estágio Curricular Supervisionado é um retrato vivo da prática docente e de que o professoraluno tem muito a dizer, a ensinar, expressando sua realidade, a de seus colegas de profissão e de seus alunos, que no mesmo tempo histórico vivenciam os mesmos desafios e as mesmas crises na escola e na universidade.

Sem dúvida nenhuma, o Estágio foi desenvolvido para proporcionar ao aluno em aproximação à realidade na qual atuará, mas, assim, o mesmo se afasta de uma compreensão que até então era considerada como uma prática do curso. Com essa conotação de intencionalidade e burocratização (fichas, observações e avaliações), podemos estar tirando um caminho no qual o mesmo deveria estar, que é entrar em um conceito de reflexão a partir da realidade encontrada. Este é o momento de analisarmos e nos questionarmos criticamente, procurando a partir destas, encontrar soluções vindas das teorias. 


\section{Volume 1 - Número 14 - Primeiro Semestre de 2013}

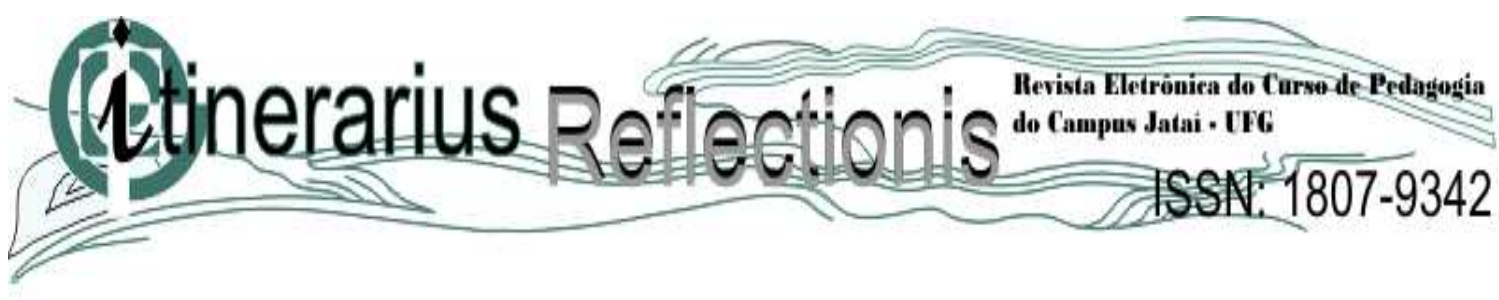

Para Freitas (1992) a questão não está em aumentar a prática e diminuir a teoria ou vice-versa, mas em adotar uma nova forma de produzir o conhecimento, este que é resultado de um processo de formação do educador, que se apropria muitas vezes somente dos pensamentos repassados pelo seu orientador, deixando de lado uma teoria de reflexão da realidade encontrada no contexto escolar em que este foi inserido.

De acordo com Krug (2010) é no decorrer das atividades do Estágio Curricular Supervisionado que se tem a possibilidade de melhor detectar o tipo de formação que os alunos receberam, e que por este motivo, os problemas encontrados nesta disciplina, por vezes, extrapolam os seus limites de disciplina final do currículo dos cursos de Licenciatura. Assim sendo, pode-se estabelecer duas funções da Prática de Ensino, uma corretiva e uma formativa.

A função corretiva se refere à atenuação das deficiências dos alunos-mestres trazidas no bojo de sua formação profissional, bem como suas características pessoais, entendidas estas como aquelas condições psicofísicas individuais associadas às suas aptidões para a carreira profissional.

A partir destas duas funções do Estágio Curricular Supervisionado podem ser desenvolvidos os meios para prover os alunos-mestres de comportamentos precisos para o ensino. Nestes programas de formação de professores baseados na racionalidade técnica, o Estágio Curricular Supervisionado representa um importante momento de transição na vida do acadêmico, elevando o seu grau de autonomia, se comprometendo eticamente com ações pedagógicas próprias de um professor (PICONEZ apud WIGGERS, 1994).

\section{Considerações finais}

Concluímos que na condição de seres humanos, não podemos viver sem fazer inúmeros julgamentos que afetam nossas vidas. Assim como temos direito à satisfação de nossas necessidades, estamos sempre na busca do melhor, do aprimoramento, do 


\section{Volume 1 - Número 14 - Primeiro Semestre de 2013}

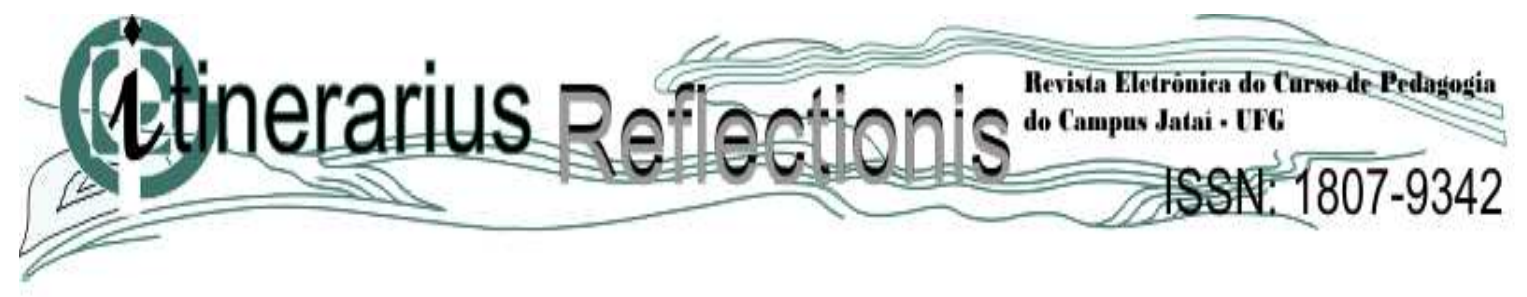

conhecimento, que na nossa sociedade é o que prevalece. Esse conhecimento, que é buscado nas instituições escolares e, posteriormente, nas universidades, que tem por função a disseminação do saber e, nesta função, se inclui a organização e o oferecimento de cursos de formação profissional (LIMA, 1994).

Em relação à Educação Física Licenciatura, a situação da formação profissional não é diferente dos demais cursos de formação de professores (DARIDO, 1995). Nesse sentido, a formação profissional em Educação Física tem se apresentado como questão de discussões, tanto na bibliografia como em encontros científicos (NASCIMENTO, 1991).

Através da bibliografia podemos observar que a Licenciatura em Educação Física continua sendo uma preparação profissional, sendo que possui uma visão de que estamos presos à função social da escola, que é pré-determinada pelo estado (poder) historicamente, mas compreendemos que estes são problemas da sociedade brasileira.

Nesta perspectiva, ressaltamos que é na formação inicial que obtemos, como futuros professores, nossos conhecimentos científicos e pedagógicos, estas que são necessárias para enfrentarmos a carreira docente. Nela que o futuro professor começa a exercer a sua função docente, função esta que será 'continuum' segundo Marcelo Garcia (1999), pois a formação inicial não deve oferecer produtos acabados, mas sim encarado como um longo e diferenciado processo de desenvolvimento profissional.

\section{REFERÊNCIAS}

BARROS, José M. de C. Educação Física na UNESP de Rio Claro: Bacharelado e Licenciatura. Motriz, Rio Claro, v. 1, n. 1, p. 71-80, jun., 1995.

BRASIL. Conselho Nacional de Educação. Resolução CNE/CP n. 01, 18 de fevereiro, 2002.

2004.

. Conselho Nacional de Educação. Resolução CNE/CES nº. 07, 31 de março, 


\section{Volume 1 - Número 14 - Primeiro Semestre de 2013}

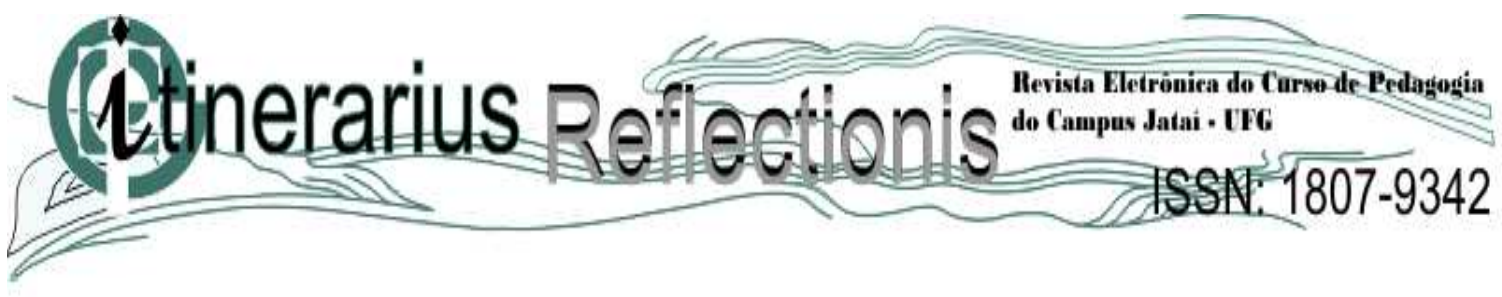

CARREIRO DA COSTA, Francisco A.A. Formação de professores: objetivos, conteúdos e estratégias. Revista de Educação Física/UEM, Maringá, v.5, n.1, p.26-39, 1994.

DARIDO, Suraya C. Teoria, prática e reflexão na formação profissional em Educação Física. In: SIMPÓSIO PAULISTA DE EDUCAÇÃO FÍSICA, V, 1995, Rio Claro. Anais, Rio Claro: UNESP, 1995. p.12.

ENGUITA, Mariano F. Trabalho, escola e ideologia: Marx e a crítica a educação. Porto Alegre: Artes Médicas Sul, 1993.

FREITAS, Luiz C. de. Em direção a uma política para a formação de professores. Revista Em aberto, Brasília, n.54, abr./jun., 1992.

FREIRE, Paulo. Pedagogia da autonomia: saberes necessários à prática educativa. 8. ed. Rio de Janeiro: Paz e Terra, 1996.

FRIGOTTO, Gaudêncio (Org) Educação e crise do trabalho: perspectivas de final de século. Petrópolis: Vozes, 1998.

GAMBOA, Silvio S. (Org.). Pesquisa educacional: quantidade-qualidade. São Paulo: Cortez, 1995.

GIL, Antônio C. Métodos e técnicas de pesquisa social. São Paulo: Atlas, 2002.

GODOY, Arilda S. Pesquisa qualitativa: tipos fundamentais. Revista de Administração de Empresas, São Paulo, v.35, n.3, p.20-29, mai./jun., 1995.

IVO, Andressa A.; KRUG, Hugo N. O Estágio Curricular Supervisionado e a formação do futuro professor de Educação Física. Revista Digital Lecturas: Educación Física y Deportes, Buenos Aires, a.13, n.127, p.1-18, diciembre, 2008. Disponível em: http://www.efdeportes.com/efd127/a-formacao-do-futuro-professor-de-educacao-fisica.htm. Acessado em: 24 mai. 2013.

KINCHELOE, Joel L. Tradução de Nize Maria Campos Pellanda. A formação do professor como compromisso político: mapeando o pós-moderno. Porto Alegre: Artes Médicas, 1997. 


\section{Volume 1 - Número 14 - Primeiro Semestre de 2013}

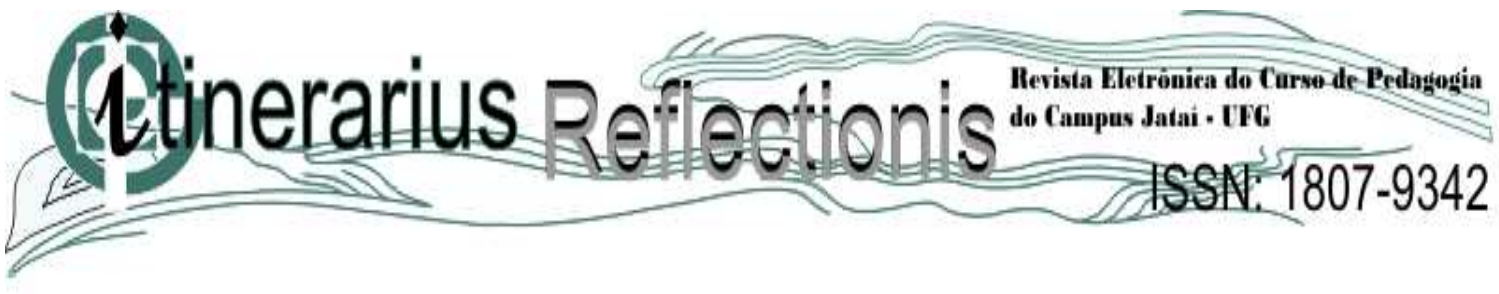

KRUG, Hugo N. Formação de professores reflexivos: ensaios e experiências. Santa Maria: O Autor, 2001a.

A construção do conhecimento prático do professor de Educação Física. 2001. 254 f. Tese (Doutorado em Educação) - Universidade Federal de Santa Maria, Santa Maria, 2001b.

As contribuições na aprendizagem docente do encadeamento dos Estágios Curriculares Supervisionados I-II-III na percepção dos acadêmicos da Licenciatura em Educação Física do CEFD/UFSM. Revista Digital Lecturas: Educación Física y Deportes, Buenos Aires, a.14, n.142, p.1-16, marzo, 2010. Disponível em: http://www.efdeportes.com/efd142/contribuicoes-na-aprendizagem-docente-emeducacao-fisica.htm. Acessado em: 24 mai. 2013.

LIMA, Jorge R.P. Caracterização acadêmica e profissional da Educação Física. Revista Paulista de Educação Física, São Paulo, v.8, n.2, p.54-67, 1994.

LUCKESI, Cipriano C. Avaliação da aprendizagem escolar. São Paulo: Cortez, 1999.

MARCELO GARCIA, Carlos. A formação de professores: novas perspectivas baseadas na investigação sobre o pensamento do professor. In: NÓVOA, Antônio. (Coord.). Os professores e sua formação. Lisboa: Publicações Dom Quixote, 1992. p.51-76.

. A formação de professores: novas perspectivas baseadas na investigação sobre o pensamento do professor. In: NÓVOA, Antônio. (Coord.). Os professores e sua formação. Lisboa: Publicações Dom Quixote, 1999. p.51-76.

MARQUES, Marta N.; ILHA, Franciele R. da S.; KRUG, Hugo N. O acadêmico de Educação Física do CEFD/UFSM em situação de estágio: aprendizagem, desenvolvimento e contribuições deixadas aos escolares. Boletim Brasileiro de Educação Física, Brasília, n.74, p.1-11, mai./jun., 2009. Disponível em http://boletimef.org/biblioteca/2296/O-academico-deEducacao-Fisica-do-CEFD-UFSM-em-situacao-de-estagio Acessado em: 20 mar. 2013.

MARQUES, Marta N.; KRUG, Hugo N. Os aspectos positivos e negativos sentidos pelos acadêmicos de Educação Física do CEFD/UFSM durante a realização do Estágio Curricular Supervisionado. Revista Digital Lecturas: Educación Física y Deportes, Buenos Aires, 


\section{Volume 1 - Número 14 - Primeiro Semestre de 2013}

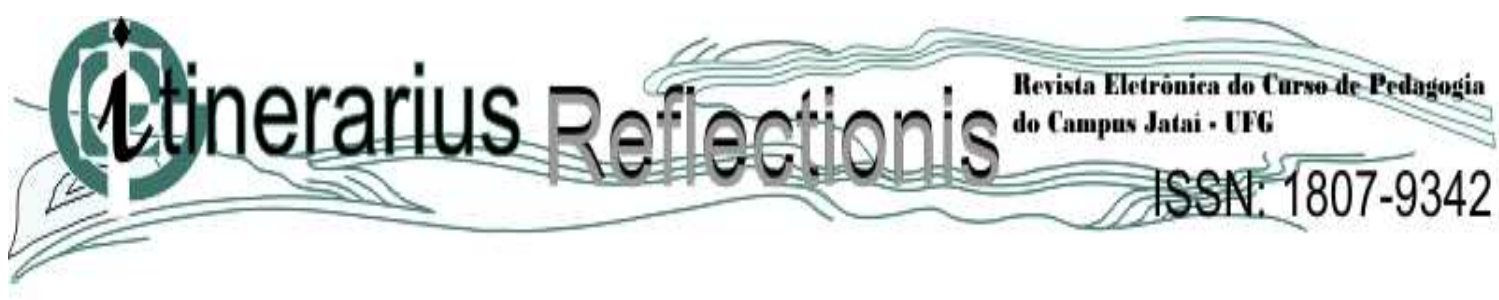

a.15, n.147, p.1-6, agosto, 2010. Disponível em: http://www.efdeportes.com/efd147/aspectospositivos-do-estagio-curricular-supervisionado.htm. Acessado em: 24 mai. 2013.

NASCIMENTO, Juarez V. do. Nova proposta curricular do curso de Educação Física na Universidade Estadual de Maringá. Revista de Educação Física/UEM, Maringá, v.2, n.1, p.04-09, 1991.

NAGLE, Jairo. As universidades e suas licenciaturas: educadores $\mathrm{x}$ pesquisadores. In: FISCHMANN, R. (Org). Universidade, escola e formação de professores. São Paulo: Brasiliense, 1987.

NÓVOA, Antônio. Os professores em busca de uma autonomia perdida. Ciências da Educação em Portugal, Porto: Edições Afrontamento, p.521-531, 1990.

PETRICA, João M. A formação de professores de Educação Física nas escolas superiores de Educação Física. Revista de Educação Física e Desporto Horizonte, Lisboa, v.IV, n.22, p.128-135, 1987.

PÉREZ GÓMEZ, Angel. O pensamento prático do professor. In: NÓVOA, A. (Coord.). Os professores e sua formação. Lisboa: Publicações Dom Quixote, 1992. p.15-34.

PIMENTA, Selma G.; LIMA, Maria do S.L. Estágio e docência. São Paulo: Cortez, 2004. (Coleção Docência em Formação. Série Saberes Pedagógicos).

SAVIANI, Demerval. Marxismo e Educação. Revista Princípios, n. 82, São Paulo, dez.2005/jan.2006. p. 37-45.

SCHÖN, Donald A. Formar professores como profissionais reflexivos. In: NÓVOA, A. (Org.). Os professores e a sua formação. Lisboa: Publicações Dom Quixote, 1992. p.77-92.

Educando o profissional reflexivo: um novo design para o ensino e a aprendizagem. Porto Alegre: Artmed, 2000.

STEINHILBER, Jorge. Profissional de Educação Física: existe? Rio de Janeiro: Sprint, 1996. 


\section{Volume 1 - Número 14 - Primeiro Semestre de 2013}

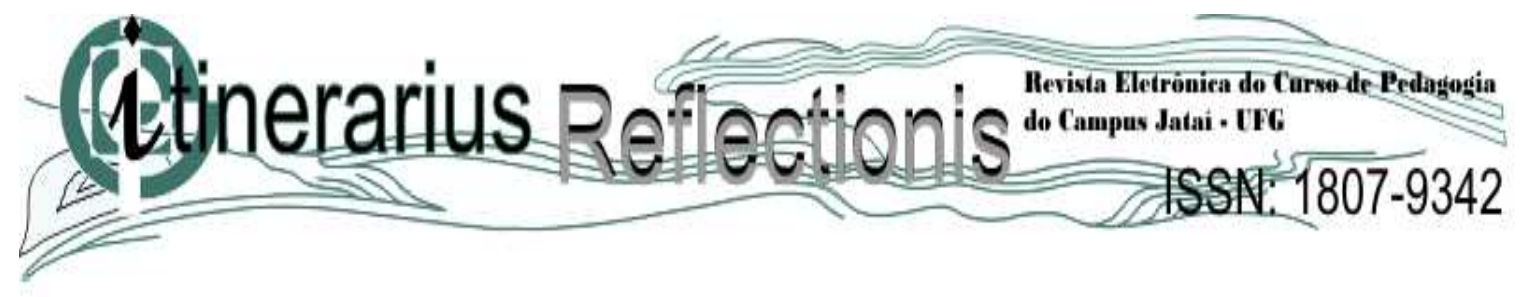

TEIXEIRA, Anísio. Educação não é privilégio. 5. ed. Rio de Janeiro: Editora UFRJ, 1994.

TELlES, Cassiano; KRUG, Hugo N. O Estágio Curricular Supervisionado e a formação do futuro professor de Educação Física. Revista Digital Lecturas: Educación Física y Deportes, Buenos Aires, a.13, n.127, p.1-18, diciembre, 2011. Disponível em http://www.efdeportes.com. Acessado em 04/01/2013.

TRIVIÑOS, Augusto N.S. Introdução à pesquisa em ciências sociais. São Paulo: Atlas, 1987. 174p.

ZEICHNER, Ken. A formação reflexiva de professores, idéias e práticas. Lisboa: EDUCA, 1993.

Novos caminhos para o practicum: uma perspectiva para os anos 90. In: In: NÓVOA, A. (Org.). Os professores e a sua formação. Lisboa: Publicações Dom Quixote, 1992. p.115-138

WIGGERS, Ingrid D. Estágio Supervisionado de Educação Física: memória das experiências de ensino. Revista Motrivivência, Florianópolis, a.V, n.5/6/7, p.102-110, 1994. 